\title{
A case of neurocysticercosis with
} an unusual presentation on high seas

\author{
Ajit C. Kulkarni
}

Medical Centre, Mumbai, India

\begin{abstract}
Every seafarer undergoes a medical examination prior to joining a ship. Some disorders cannot be detected and they may appear while at sea. Diagnosing and managing them becomes extremely difficult for the Master being the caregiver on board. Large crude carriers often perform long voyages and due to their sheer size, do not enter any port. Helicopter evacuation of a sick or injured crew is the norm. They operate under strict chartering time lines which do not permit deviation from course. A case of hemiparesis on left side of body in a young hitherto healthy seafarer which was later diagnosed as a case of neurocysticercosis is described.
\end{abstract}

(Int Marit Health 2020; 71, 4: 278-280)

Key words: medical examination of seafarers, Radio Medical Advice, neurocysticercosis, seizure, Taenia solium

\section{INTRODUCTION}

Seafarers are required to undergo a medical examination prior to sailing to reduce risks to crew members and for the safe operations of the ship as well as to safeguard their personal health and safety at sea. Aim of the medical examination is to ensure that the seafarer is medically fit to perform his or her routine and emergency duties at sea and is not suffering from any medical condition likely to be aggravated by service at sea, to render him or her unfit for service or to endanger the health of other persons on board [1].

Master of the vessel is the caregiver on board and is required to have undergone a course in medical care as per the International Maritime Organisation (IMO) Standards of Training Certification and Watchkeeping (STCW) convention [2]. Due to advances in communication, he is able to seek medical advice by telephone, emails or video calls but handling any unusual medical condition is challenging and may also have a demoralizing effect on the crew.

\section{CASE REPORT}

Previously healthy 24 years old Indian $4^{\text {th }}$ Engineer, was sailing on a Hong Kong registered 320,051 DWT crude carrier for the past 10 weeks. Vessel was $333 \mathrm{~m}$ in length
(LOL) and had a speed of 13 knots per hour. The vessel had a mixed crew of Indian, Philippine and Indonesian nationals on board. The vessel was sailing in ballast to reach a loading port in Persian Gulf in 5 days.

The $4^{\text {th }}$ Engineer woke up after a normal undisturbed sleep and realised that he had lost control in his left upper and lower limbs. He was dizzy and unsteady getting out of bed and walk to the rest room. He was unable to hold his toothbrush in his left hand to squeeze toothpaste on it. He called the Chief Engineer who in turn alerted the Master about the status of the $4^{\text {th }}$ Engineer. After examining the patient, the Master called the author for Radio Medical Advice, being the medical Consultant to the Vessel Management Company. There was no history of exertion, no syncope, speech was normal. No headache. No past history of any head injury. Other than weakness over the left side of the body and pain over left orbital area, the patient had no symptoms. He had voided urine in the morning without any difficulty. Pulse, respiration and blood pressure were within normal limits.

Master was advised steps in examining the central nervous system. Patient was fully conscious. Mental status examination with reference to attention, orientation and memory, both past and recent were normal. No signs 
of meningeal irritation. Examination of pupils and cranial nerves was normal. He needed to make special effort to carry out any activity with left upper and lower limbs. Power in left upper and lower limbs was found to be 4/5. Gait was unsteady. Romberg's test with eyes closed was positive.

A provisional diagnosis of subarachnoid haemorrhage was made; however, there was no headache which normally accompanies such an episode. Patient was advised complete bed rest to be watched over by another crew member.

Operations manager was contacted by the Master and a three way conference call was held. Seriousness of the situation was conveyed and also that the seafarer needs to be evacuated ashore for hospitalisation and investigation was impressed upon. Vessel position was $12^{\circ} 50 \mathrm{~N}$ and $73^{\circ} 29 \mathrm{E}$, almost due west of Mangalore port on West coast of India. Well within the range of helicopter evacuation if the patient's condition deteriorated. Patient's condition was closely monitored every 8 hours. He remained dizzy, fully conscious and had had cereal as meal. After 24 hours, patient's condition remained unchanged. Small subarachnoid bleeds often resolve by itself and a decision was taken to sign off the patient in the loading port. Sailing along the West coast of India, the vessel remained within helicopter evacuation range from India and then Oman. The Agent in loading port was accordingly instructed that the crew member should be signed off and put on the first available flight to Mumbai, India. Over the next four days patient's condition remained unchanged. Blood pressure, respiration was normal, bladder and bowel control was normal. No headache. Patient was landed ashore in the Pilot boat, immigration formalities completed and he boarded a flight and arrived in Mumbai same day late evening. On arrival, he was taken to a hospital on a priority basis and on admission magnetic resonance imaging brain was carried out to diagnose the condition and plan line of treatment.

Magnetic resonance imaging study detected a solitary cystic lesion high up in right parietal lobe. The lesion was centrally hyperintense on both $\mathrm{T} 2 \mathrm{~W} 2$ and inversion recovery magnetic resonance images with a hyper intense rim and surrounding vasogenic oedema. A small eccentric nodule was seen within the lesion. Post contrast image revealed peripheral enhancement. The findings were consistent with neurocysticercosis (NCC) (Fig. 1).

His liver function tests were normal. Fundus examination was normal. He was prescribed Tab Albendazole $400 \mathrm{mg}$ twice daily for 8 days. Symptom exacerbation is common during the first week after antiparasitic treatment is initiated. Use of steroids decreases this. Dexamethasone $0.1 \mathrm{mg} / \mathrm{kg}$ in three divided doses for 10 days was prescribed for the same to be tapered off [3]. As no active treatment was required, he was permitted to travel to his place of residence and consult a neurophysician for follow up.

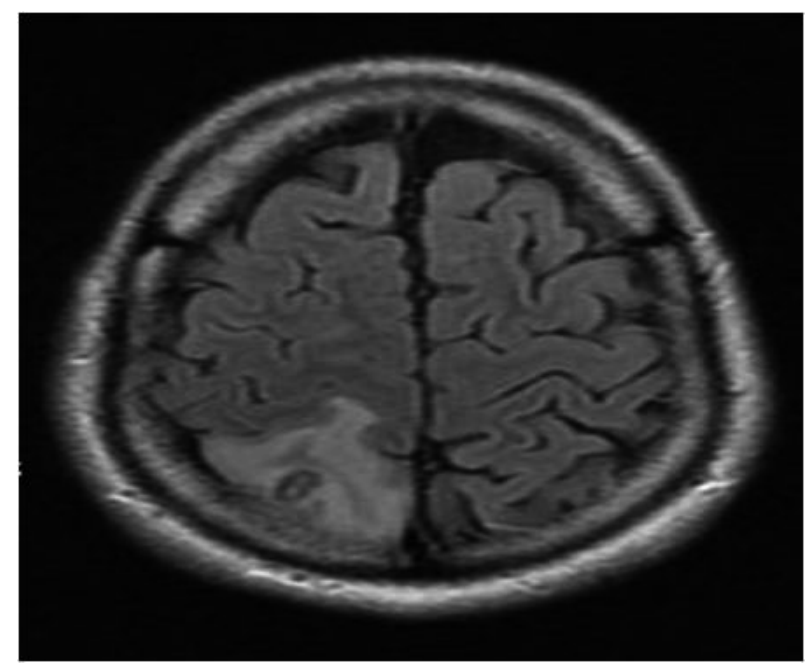

Figure 1. Solitary cystic lesion in parietal lobe (all markings are deleted for confidentiality of identity of the patient)

\section{DISCUSSION}

Seizure is the most common symptom in a case of NCC. To treat a seizure on board a vessel would not be an easy task. Midazolam (benzodiazepam) injection is the only medication recommended to be carried on board to treat seizure/epilepsy. It is to be administered intravenously, intramuscularly or intramucosal in the nostrils [4]. Presence of a seriously ill crew member on board demoralizes the rest of the crew extensively.

Neurocysticercosis is a parasitic disease caused by metacestodal stage of Taenia solium, and is one of the most common causes of epilepsy in man. The commonest manifestation of NCC in humans is acute symptomatic seizures. Seizures can be generalised, focal or rarely myoclonus and acquired epileptic aphasia. It affects adults in their third or fourth decade of life [5].

Neurocysticercosis is one of the most important neglected tropical diseases in the third world countries. Cysticercosis is a serious public health problem especially in resource poor and developing countries including India. It is considered as a biological marker of social and economic development, it predominantly affects adults in their third or fourth decade of life [6].

Life cycle of Taenia solium comprises two natural hosts, man acts as definitive host harbouring the adult tape worm in the intestine passing the eggs in faeces. While pig is the intermediate host which ingests some of these eggs leading to development of cysticerci in internal organs like muscle and brain. Humans become infected by consuming pork contaminated with cysticerci. The scolex of adult worm is equipped with four lateral suckers and a rostellum is armed bearing 25-50 hooklets by which it attaches itself to the internal mucosa (Fig. 2). 


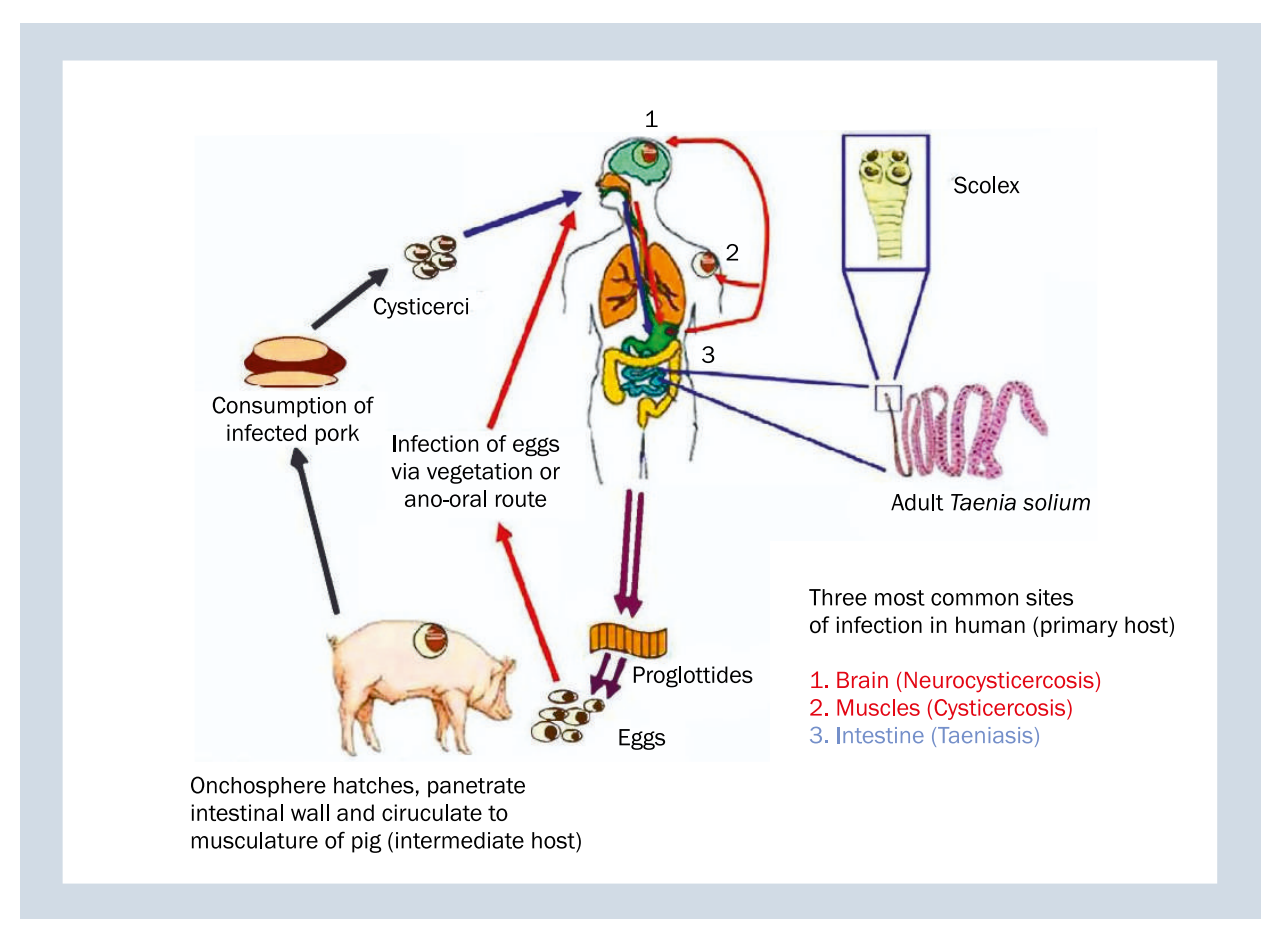

Figure 2. Life cycle of Taenia solium

In the present case, the patient was a vegetarian and had never consumed pork. In India, in endemic areas, there is a large population that is vegetarian and do not consume pork. This significant number of vegetarians amongst NCC cases suggest other mode of transmission, e.g. contaminated salads [7].

Cysticercosis has been categorised as a potentially preventable and eradicable disease. Tapeworm carriers are potential target for the control of cysticercosis. Emphasis should be on health education and mass administration of anthelminthics in endemic areas to remove tape worm carriers. Education of community based sanitation, building and usage of latrines and proper disposal of night soil coupled with healthy animal husbandry practices play a major role in control and eradication.

\section{CONCLUSIONS}

Large number of seafarers hail from South East Asia and China where pork is consumed extensively. Screening every asymptomatic seafarer for NCC is not possible. Instead all reporting for pre-employment medical examination (PEME) could be administered tab Albendazole $400 \mathrm{mg}$ as a single dose broad spectrum anthelmintic as a cost effective measure. Food handlers should be additionally treated with anti-amoebic medication.

Patient remained prone to seizure and he may need anti-epileptic drugs and long convalescence. He would not be considered fit for sea service till 1 year after stoppage of anti-epileptic drugs. He was thus lost to follow up.

\section{REFERENCES}

1. Guidelines on the Medical Examination of Seafarers. International Labour Office Geneva, IMO. ISBN 978-92-2-127462-9.

2. International Maritime Organization: Section A-VI/4, STCW Conference. 2/34, 3 August 2010.

3. Garcia HH, Nash T, Brutto OD. Clinical symptoms, diagnosis, and treatment of neurocysticercosis. Lancet Neurol. 2014; 13(12): 1202-1215, doi: 10.1016/s1474-4422(14)70094-8.

4. International Guide for Ships. 3rd Edition, World Health Organization. 2007. ISBN 978924 154720. Page 118-121.

5. Malla BA. An overview of neurocysticercosis. J Pharmacognosy Phytochemistry. 2018; 7(6): 303-312.

6. Prasad KN, Prasad A, Verma A, et al. Human cysticercosis and Indian scenario: a review. J Biosci. 2008; 33(4): 571-582, doi: 10.1007/ s12038-008-0075-y, indexed in Pubmed: 19208982.

7. Varma A, Gaur KJ. The clinical spectrum of neurocysticercosis in the Uttaranchal region. J Assoc Physicians India. 2002; 50: 1398-1400, indexed in Pubmed: 12583469. 